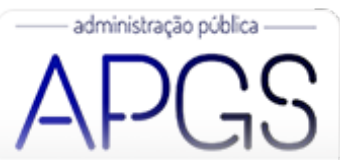

Administração Pública e Gestão Social ISSN: 2175-5787

apgs@ufv.br

Universidade Federal de Viçosa

Brasil

\title{
Avaliação da Eficiência do Programa Bolsa Família nos Municípios do Paraná
}

Cattelan, Renata; Ribeiro de Mello, Gilmar; Mendes Bezerra, Fernanda

Avaliação da Eficiência do Programa Bolsa Família nos Municípios do Paraná

Administração Pública e Gestão Social, vol. 12, núm. 3, 2020

Universidade Federal de Viçosa, Brasil

Disponible en: http://www.redalyc.org/articulo.oa?id=351563312002

Esta obra está bajo una Licencia Creative Commons Atribución-NoComercial-SinDerivar 3.0 Internacional. 


\section{Avaliação da Eficiência do Programa Bolsa Família nos Municípios do Paraná \\ Evaluation Of The Efficiency Of The Bolsa Família Program in the Municipalities of Paraná \\ Evaluación de la Eficiencia del Programa Bolsa Familia en los Municipios del Paraná}

Renata Cattelan

Universidade Estadual do Oeste do Paraná - UNIOESTE/

Campus de Toledo, Brasil

renata.cattelan@gmail.com

Gilmar Ribeiro de Mello

Universidade Estadual do Oeste do Paraná - UNIOESTE/

Campus de Francisco Beltrão, Brasil

gilmarribeirodemello@gmail.com

Fernanda Mendes Bezerra

Universidade Estadual do Oeste do Paraná - UNIOESTE/

Campus de Francisco Beltrão, Brasil

ferpompeia@gmail.com
Redalyc: http://www.redalyc.org/articulo.oa? $\mathrm{id}=351563312002$

Recepción: 22 Septiembre 2017

Aprobación: 01 Marzo 2019

Publicación: 01 Julio 2020

\section{Resumo:}

Este artigo procurou avaliar a eficiência relativa dos municípios paranaenses na aplicação dos valores repassados pelo Programa Bolsa Família nos anos de 2006 e 2015, levando em consideração os resultados de três variáveis consideradas condicionalidades do programa. $\mathrm{Na}$ área de saúde, a imunização por cobertura vacinal total, e na área de educação, a taxa de aprovação e a taxa de não distorção idade/série, utilizadas como outputs. Os inputs selecionados foram o número de famílias beneficiárias e o valor em dinheiro repassado ao município pelo programa. A metodologia utilizada foi a Análise Envoltória de Dados (DEA). Os resultados demonstraram que houve melhoras nos outputs de 2006 para 2015, mas que, tendo em vista os recursos aplicados pelo programa, os resultados poderiam ter sido melhores. Indica-se que, para aumentar a eficiência, alternativas estratégicas de geração de emprego e renda sejam inseridas no programa para que o ciclo de desigualdades e pobreza possa ser rompido.

PalaVras-Chave: Programa Bolsa Família, Análise Envoltória de Dados (DEA), Municípios do Paraná.

\section{Abstract:}

This paper sought to evaluate the situation regarding the municipalities of the state of Paraná, in Brazil, in the application of the values released by the Bolsa Família Program in the years 2006 and 2015, taking into account the results of the three variables considered conditionalities of the program. In the area of health by immunization by total vaccination coverage, in the area of education the approval rate and the non-distortion rate age/grade, as outputs. The inputs selected were the number of beneficiary families and the amount of money passed on to the municipality by the program. The methodology used was the Data Envelopment Analysis (DEA). The results show that there were improvements in outputs from 2006 to 2015, but that the results could have been better. It is pointed out that to increase efficiency, alternative employment and income generation must be included in the program so that the cycle of inequalities and poverty can be broken.

KEYwords: Bolsa Família Program, Data Envelopment Analysis (DEA), Municipalities of Paraná.

\section{Resumen:}

Este artículo buscó evaluar la eficiencia relativa de los municipios del estado de Paraná, en Brasil, en la aplicación de los valores repasados por el Programa Bolsa Familia en los años 2006 y 2015, teniendo en cuenta los resultados de tres variables consideradas condicionalidades del programa. En el área de salud, la inmunización por cobertura vacunal total, y en el área de educación, la tasa de aprobación y la tasa de no distorsión edad/serie, utilizadas como outputs. Los insumos seleccionados fueron el número de 
familias beneficiarias y el valor en efectivo transferido al municipio por el programa. La metodología utilizada fue el Análisis por Envoltura de Datos (DEA). Los resultados demostraron que hubo mejoras en las salidas de 2006 para 2015, pero, teniendo en cuenta los recursos aplicados por el programa, los resultados podrían haber sido mejores. Se indica que, para aumentar la eficiencia, las alternativas de generación de empleo y renta deben incluirse en el programa para que el ciclo de desigualdades y pobreza se pueda romper.

Palabras Clave: Programa Bolsa Familia, Análisis por Envoltura de Datos (DEA). Municipios de Paraná.

\section{INTRODUÇÃO}

O processo de construção histórica do homem, assim como o desenvolvimento das sociedades e das relações sociais, esteve permeado de contradições, de desigualdades e de pobreza. A pobreza não é contemporânea e transformar esta realidade é o objetivo de muitos estudos realizados ao longo do tempo.

Reduzir as desigualdades soa menos utópico do que acabar com a pobreza e os esforços por muito tempo têm focado em dar condições de vida àqueles que vivem à margem da sociedade. Vários países criaram programas que auxiliam na redução das desigualdades sociais. No Reino Unido, por exemplo, há um programa similar ao Programa Bolsa Família (PBF) brasileiro, denominado Child benefit, que faz transferências unilaterais de renda para famílias que tenham renda inferior a 50.000 libras anuais (Claim Child Benefit, 2017). A Alemanha possui um programa chamado Arbeitslosengeld II, semelhante ao seguro desemprego brasileiro, que beneficia não somente os desempregados, mas aqueles que não são capazes de trabalhar e necessitam de assistência (Deutschland, 2017).

$\mathrm{O}$ PBF, objeto de análise desta pesquisa, é uma política pública implantada pelo Governo Federal para redução da pobreza e consiste na transferência unilateral de renda da qual as famílias que a recebem ficam condicionadas, na área da educação, a manter crianças e adolescentes na educação regular e, na área da saúde, a manter as vacinas atualizadas, realizar tratamento pré-natal e acompanhamento de gestantes, crianças e adolescentes, no que tange à assistência social.

A desigualdade como problema social dentro de um ciclo é quebrada pelo acesso a condições básicas de bem-estar, dentre elas a saúde e a educação como prioritárias. Neste contexto, a problemática desta pesquisa é: Quais municípios paranaenses são mais eficientes em aplicar os valores do PBF e como se comportam os setores de saúde e educação, considerados condicionalidades do programa?

O objetivo desta pesquisa é avaliar a eficiência relativa ${ }^{[i]}$ dos municípios paranaenses na utilização dos recursos do PBF, criando uma fronteira de eficiência e identificando os municípios que ficam abaixo desse nível de eficiência no ano de 2006 e no ano de 2015, a fim de fazer um comparativo temporal.

O Brasil ainda é um dos países mais desiguais do mundo, mesmo mostrando melhoras nas últimas décadas. Assim, os programas de transferência de renda vieram para amenizar distorções que prejudicam o bem-estar da população que vive com uma renda inferior àquela considerada mínima. O PBF dá foco a esferas específicas que se tornam importantes medidas de bem-estar social, como é o caso da saúde e da educação. Em um universo de recursos escassos e de necessidade de eficiência, esses recursos devem ser bem empregados. Nesse sentido, esta pesquisa se justifica pela tentativa de avaliar os investimentos e os retornos do PBF mensurados pelas variáveis que o programa promete afetar, a saúde e a educação.

Este artigo é composto, além desta introdução, por uma revisão de literatura, a fim de contextualizar e apresentar estudos semelhantes ao tema, uma seção destinada a descrever o processo metodológico utilizado, bem como a base de dados e o recorte geográfico e temporal, uma seção com a apresentação e análise dos dados e, por fim, as considerações finais sobre a pesquisa. 


\section{REVISÃO DA LITERATURA}

Esta seção tem por objetivo contextualizar o tema da pesquisa, bem como analisar estudos semelhantes quanto à metodologia ou quanto ao objetivo, a fim de comparar resultados em âmbito nacional e internacional.

\section{A pobreza e seus encadeamentos na sociedade}

Tão presente na história, acostumou-se a pensar a pobreza como uma situação inerente à sociedade moderna. Kageyama e Hoffman (2006) apontam que o entendimento de pobreza depende da noção de privação que pode incluir elementos materiais, sociais e culturais. Segundo Hagenaars e Vos (1988, p. 212), as definições de pobreza encontram-se em geral dentro de três classes: "Pobreza é ter menos que um mínimo objetivamente definido; Pobreza é ter menos que os outros na sociedade; Pobreza é sentir que não tem o suficiente para seguir a diante" ${ }^{[i i]}$.

As três categorias, resumidas em pobreza absoluta, relativa e subjetiva, respectivamente, compreendem outros encadeamentos de definições de pobreza entre elas. Com relação à pobreza absoluta, necessidades básicas relativas à renda (proporção de gastos com alimentos, energia, transporte, educação, aluguel, etc.). No tocante à pobreza relativa, uma privação de bens considerados comuns no ambiente daquele indivíduo ou família. Com relação à pobreza subjetiva, questionar as pessoas sobre o que elas consideram necessidades básicas e comparar o valor desses elementos com a renda. Além destes, ainda se usa muito comumente a definição de renda mínima oficial (Kageyama \& Hoffman, 2006). No Brasil, uma das definições oficialmente adotadas para a linha de pobreza e extrema pobreza é em relação à renda mensal per capita familiar, de até $\mathrm{R}$ $\$ 170,00$ e de $\mathrm{R} \$ 85,00$, respectivamente (Decreto $\mathrm{n}^{\circ} 8.794,2016$ ).

Pensar a pobreza em termos históricos leva o Brasil a um legado de desigualdades que foram e são perpetuadas. Em pesquisa recente, o Banco Mundial divulgou que o Brasil passará, em 2017, por um aumento de 2,5 a 3,6 milhões de pessoas vivendo na miséria, em um cenário que desfruta de instabilidade política e crises econômicas prolongadas. O perfil dos "novos pobres", como tratado pelo organismo, é de indivíduos com menos de 40 anos que vivem no meio urbano e que cursaram pelo menos o ensino médio (Organização das Nações Unidas [ONU], 2017).

Como base para esta pesquisa se utilizará o conceito definido pelo próprio PBF no que diz respeito à pobreza e à extrema pobreza, levando em consideração as faixas de renda definidas pelo Governo Federal no ano de 2016.

\section{As políticas sociais e de transferência de renda: o caso brasileiro}

A evolução histórica das políticas públicas de cunho social se desenvolveu à luz de necessidades econômicas e políticas. Não por menos a década de 1930 representa um marco neste aspecto, quando o país passava por uma crise econômica de proporções mundiais que, ademais, daria base para uma passagem de uma economia agroexportadora para urbano-industrial (Silva, 2007).

O período sob o comando de Getúlio Vargas (1930 a 1945 e 1951 a 1954) foi marcado por diversos planos na esfera social. Segundo Costa, Vita e Pralon (1998), era a resposta às agitaçóes operárias que vinham ocorrendo. As questões sociais passam a compor e a tomar o centro das atividades governamentais e esse governo contempla diversas legislações trabalhistas que procuram solucionar as tensões criadas entre empregados e empregadores.

Nos governos seguintes as alterações feitas nesses programas não seriam muito significativas. De modo geral, seriam mantidos até a reformulação da Constituição Federal Brasileira em 1988. Vale citar que essas 
políticas tinham por objetivo manter essas carências sociais dentro de certos limites e evitar embates entre classes (Costa, Vita, \& Pralon, 1998).

A Constituição Federal de 1988 permitiu que a Assistência Social fosse pensada como um direito e garantida por uma lei nacional. Em seu Cap. II, seção IV, a Constituição dispõe sobre a assistência social colocando que ela deverá ser prestada a quem dela necessitar, visando proteger a família, promover a integração no mercado de trabalho, assim como a participação da população através de entidades representativas (Constituição Federal, 1988).

Em 1993 foi sancionada a Lei Orgânica da Assistência Social, que a colocava como dever do Estado. Além disso, um importante avanço diz respeito à descentralização dos níveis de execução da lei (Lei no 8.742, 1993).

Debates sobre as transferências de renda ganharam mais visibilidade internacional a partir da década de 1980, visto que as transformações decorrentes da revolução tecnológica, do início da globalização das informações e das mudanças no mercado de trabalho fizeram com que a questão social fosse cada vez mais pertinente de discussão (Silva, 2007). No Brasil, essa questão passa a ser tratada em 1991 com a aprovação do Projeto de Lei no 80/1991, que institui o Programa de Garantia de Renda Mínima (PGRM).

Silva (2007) procede a uma sistematização de momentos entre 1991 e 2003 no que diz respeito aos programas de transferência de renda. Um primeiro momento, em 1991, quando se inicia o debate sobre os programas de transferência de renda, assim como a tendência de outros países. Um segundo momento incorpora um novo debate, ainda em 1991, sobre a introdução da articulação do PGRM com a educação. O terceiro momento inicia-se em 1995, com experiências municipais na implementação de programas (descentralização). O quarto momento inicia-se em 2001, com a expansão e criação de novos programas de redução da pobreza. No ano de 2003 se inicia o quinto momento, destacado por integrar a política de transferência de renda à política econômica, unificando os programas de transferência de renda já existentes no PBF.

\section{O Programa Bolsa Família (PBF)}

Como destacado anteriormente, o PBF consolidou-se como a unificação de outros programas como o Bolsa Escola, o Bolsa Alimentação, o Auxílio Gás e o Cadastramento Único do Governo Federal. O programa passa a incluir em sua execução a obrigatoriedade de ações relacionadas à educação e à saúde por parte dos beneficiários (Lei no 10.836, 2004).

A Lei no 10.836, de 9 de janeiro de 2004, institui o Programa Bolsa Família (PBF), o qual foi regulamentado pelo Decreto no 5.209, de 17 de setembro de 2004, e alterado pelo Decreto $n^{\circ} 8.794$, de 29 de junho de 2016. O programa é gerenciado, coordenado e operacionalizado pelo Ministério do Desenvolvimento Social e Combate à Fome (MDS) (Lei no 10.836, 2004).

O Decreto $\mathrm{n}^{\circ} 8.794$ estabelece que o PBF atenda famílias em situação de pobreza e extrema pobreza, que são caracterizadas por ter renda per capita de $\mathrm{R} \$ 170,00$ e $\mathrm{R} \$ 85,00$, respectivamente. Segundo a Caixa Econômica Federal (CEF) (2017), banco responsável pelo repasse do benefício, os objetivos do programa são: "Combater a fome e promover a segurança alimentar e nutricional; Combater a pobreza e outras formas de privação das famílias; Promover o acesso à rede de serviços públicos, em especial, saúde, educação, segurança alimentar e assistência social”.

Para participar do programa, é necessário que alguns critérios de elegibilidade sejam satisfeitos, além da renda mensal per capita menor que R $\$ 170,00$, famílias que contenham gestantes, nutrizes e crianças/ adolescentes entre 0 e 17 anos. Existem, atualmente, quatro formatos de recebimento do benefício (CEF, 2017). No Quadro 1 pode-se observar uma sintetização do tipo e do valor mensal de cada benefício. 
Quadro 1 - Tipos e valores dos benefícios do PBF

\begin{tabular}{|c|c|}
\hline $\begin{array}{l}\text { Tipo de } \\
\text { benefício }\end{array}$ & Valor \\
\hline Básico & $\begin{array}{l}\mathrm{R} \$ 85,00 \\
\text { mensais }\end{array}$ \\
\hline $\begin{array}{l}\text { Variável (0 a } \\
15 \text { anos, } \\
\text { gestante e } \\
\text { nutriz) }\end{array}$ & $\begin{array}{l}\mathrm{R} \$ 39,00 \\
\text { mensais - } \\
\text { máximo de } \\
\mathrm{R} \$ 195,00\end{array}$ \\
\hline $\begin{array}{l}\text { Variável } \\
\text { Jovem }\end{array}$ & $\begin{array}{l}\mathrm{R} \$ 46,00 \\
\text { mensais - } \\
\text { máximo de } \\
\mathrm{R} \$ 92,00\end{array}$ \\
\hline $\begin{array}{l}\text { Superação } \\
\text { da Extrema } \\
\text { Pobreza }\end{array}$ & $\begin{array}{l}\text { Máximo de } \\
\mathrm{R} \$ 372,00+\text { um } \\
\text { benefício } \\
\text { mensal }\end{array}$ \\
\hline
\end{tabular}

Fonte: CEF (2017).

O benefício básico é concedido a famílias em situação de extrema pobreza. O benefício variável é destinado a famílias pobres e extremamente pobres que tenham em sua composição gestantes, nutrizes e crianças e (ou) adolescentes entre 0 e 16 anos incompletos. Cada família pode acumular até 5 benefícios. O benefício Variável Jovem contempla famílias que tenham jovens entre 16 e 17 anos, podendo acumular até 2 benefícios. Há também o benefício para superação de extrema pobreza, o valor depende de um cálculo realizado a partir da renda da família e de outros benefícios do PBF. As famílias em situação de extrema pobreza podem acumular os benefícios Básico, o Variável e o Variável Jovem, até no máximo $\mathrm{R} \$ 372,00$ e mais um benefício para superação de extrema pobreza (CEF, 2017).

Segundo o Ministério do Desenvolvimento Social (MDS), as famílias beneficiárias do programa precisam cumprir com algumas condicionalidades, contrapartidas exigidas pelo governo para fazer a transferência de renda. As condicionalidades são: a) Para crianças menores de 7 (sete) anos, a realização de todas as vacinas constantes no calendário vacinal e acompanhamento do desenvolvimento e crescimento; b) Para gestantes e nutrizes, fazer o acompanhamento pré-natal; c) Para crianças entre 6 a 15 anos, manter a matrícula escolar e a frequência de, no mínimo, 85\%; d) Para jovens de 16 e 17 anos, manter a matrícula e a frequência escolar de no mínimo 75\% (Ministério do Desenvolvimento Social e Combate à Fome [MDS], 2017).

O PBF tem caráter de execução descentralizado, cada esfera do governo é responsável por uma parte do processo. É de responsabilidade do governo federal formular procedimentos e instrumentos de gestão, dar apoio financeiro e técnico, articular entre órgãos complementares e fazer o monitoramento e avaliação do programa. Em nível estadual, cabe a execução de recursos financeiros, apoio técnico e capacitação. Os municípios fazem a gestão do programa, cadastramento, acompanhamento e identificação de famílias, e fiscalização (MDS, 2017).

Ao descrever de forma breve os passos de construção histórica pelos quais as políticas públicas e o próprio PBF passaram, ressalta-se que a redução da desigualdade social, vista como ciclo benéfico, precisa ser incentivada através da pesquisa, que é feita com o intuito de ser apoio para a tomada de decisóes e o bom gerenciamento dos recursos.

\section{Estudos relacionados ao tema}

Hespanha (2008) faz uma crítica às políticas públicas que não levam em consideração a inserção no mercado de trabalho. Executar políticas sem uma relação estrita com o emprego e a sobrevivência fora dessas políticas 
é considerado somente uma obrigação e não uma oportunidade de mudança de vida e de rompimento com a pobreza. As experiências portuguesas, conforme estudado pelo autor, tiveram sucesso, a particularidade de oferecer cursos de capacitação, o estímulo à empregabilidade e uma atitude geral de otimismo e expectativa do mercado, fizeram com que os beneficiários dessas políticas pudessem entrar no mercado de trabalho.

Martic, Novakovic e Baggia (2009) fazem um estudo a fim de compreender as possibilidades de aplicação da Análise Envoltória de Dados (DEA). Os autores concluem que há uma gama ampla para o uso da metodologia e que há um número crescente de trabalhos utilizando-a para verificar a eficiência de políticas públicas.

No estudo de Habibov e Fan (2010), utilizando a metodologia da DEA, foi analisado o desempenho da redução da pobreza no Canadá por meio de programas de assistência social. O trabalho indicou províncias canadenses mais eficientes, bem como os benchmarks para as províncias ineficientes, o que proporcionou apoio para a tomada de decisão dos gestores.

No Brasil, Cacciamali, Tatei e Batista (2010) analisaram o impacto do PBF sobre a frequência escolar e o trabalho infantil para o ano de 2004. Concluíram que o programa foi eficiente em elevar a frequência escolar, contudo, não mostrou eficiência para reduzir o trabalho infantil. Outro ponto importante levantado é de que famílias pobres de áreas rurais apresentam condições mínimas menores que as de áreas urbanas, o que demonstra a necessidade de ações específicas.

Melgarejo (2011) propôs investigar a eficiência da gestão do controle do PBF, avaliando o cumprimento dos seus objetivos e a sua descentralização. A pesquisa foi realizada por meio de aplicação de questionários com o contador e coordenadores da Coordenação Geral de Execução Orçamentária e Financeira e da Coordenação Geral de Controle Social e Ações Complementares, do MDS, assim como o gerente da Gerência Nacional do PBF na Caixa Econômica Federal. Em sua pesquisa constatou que o controle social não tem acontecido da maneira como deveria, que não há pessoal qualificado para fazer isso e que há falhas na gestão desse processo, especialmente a nível municipal, responsável pelo procedimento.

O estudo realizado nas Filipinas por Lagura (2012) analisou ações iniciadas pelo governo na tentativa de atender a políticas de bem-estar social como o programa 4Ps (Pantawid Pamilyang Philipino Program). Em sua discussão expõe que as ações específicas de transferência condicional de renda vão de encontro a problemas sociais específicos do país. Desta maneira, apesar de reconhecer que o programa atua como uma resposta imediata à pobreza, postula também que ela não é sustentável a longo prazo e que não aborda as raízes do problema. Conclui que a obrigação do governo é reavaliar a lista de beneficiários, a fim de abrandar lacunas em questões de fraude e corrupção, além de ajudar as famílias a perceberem que o programa não é a cura da pobreza, é uma ajuda para aumentar a autoestima e cumprir com suas necessidades de sobrevivência.

Brambilla (2015) realizou um estudo para verificar a eficiência da gestão do PBF nos municípios paranaenses utilizando indicadores de gestão. $\mathrm{Na}$ análise, o indicador que mais contribuiu para a qualidade da gestão foi a Taxa de Cobertura Qualificada do Cadastro e a Taxa de Atualização do Cadastro foi a que mais contribui para a redução do índice. A pesquisa também concluiu que municípios com população menor têm maiores índices de gestão.

Araújo, Araújo, Souza, Santos e Santana (2015) avaliaram a relação entre número de famílias participantes do PBF e indicadores de avaliação do programa por meio do Índice de Gestão Descentralizada. Os resultados demonstraram que quanto maior o número de famílias beneficiadas, menor o índice e menores os indicadores de monitoramento. Isso reflete falhas de gestão e as dificuldades de se articular e chegar a avaliaçóes concretas.

Santana (2016) procurou compreender a efetividade do PBF interligado às demandas sociais, o objetivo foi avaliar a gestão do programa no município de Campina Grande (PB) através de entrevistas. $\mathrm{O}$ resultado da pesquisa demonstrou que existem limitações no controle do programa a nível municipal e que não tem sido eficiente para tirar as famílias da pobreza. Os critérios utilizados no cadastro e na avaliação muitas vezes provocam distorções de interpretação e a fraca articulação entre as instâncias governamentais tem provocado falhas de gestão. 
Esta pesquisa se destina a avaliar o PBF a partir da eficiência de cada município paranaense. Assemelhase aos trabalhos citados pela utilização da metodologia e (ou) pela avaliação de uma política pública, diferenciando-se desses trabalhos pelas variáveis utilizadas ou pela avaliação da política de reforma agrária para o estado do Paraná.

\section{METODOLOGIA}

A pesquisa realizada caracteriza-se como quantitativa, pois, conforme Marconi e Lakatos (2012), tem foco em quantidades de um fator ou em termos de grandeza em situações específicas. Desta maneira, esta seção dispõe sobre o método, as variáveis, o banco de dados, o espaço geográfico e o espaço temporal utilizados na elaboração da pesquisa.

\section{Data Envelopment Analysis (DEA)}

Proposto inicialmente por Charnes, Cooper e Rhodes (1978), a Análise Envoltória de Dados, ou Data Envelopment Analysis (DEA), é uma técnica de programação não linear quantitativa, não paramétrica, que visa determinar comparativamente a eficiência de Unidades Tomadoras de Decisão (Decision Making Units [DMUs]) com base nas melhores práticas entre um conjunto de DMUs que use os mesmos inputs na produção dos mesmos outputs.

Para a medida de eficiência é utilizado o conceito de Pareto-Koopmans que demonstra um conjunto inputoutput eficiente quando: "a) Nenhum dos outputs pode ser aumentado sem que algum outro output seja reduzido ou algum input seja aumentado, ou b) Nenhum dos inputs pode ser reduzido sem que algum outro input seja aumentado ou algum output seja reduzido" (Lins, Lobo, Silva, Fiszman, \& Ribeiro, 2007, p. 986).

O objetivo da metodologia DEA é comparar os resultados obtidos (outputs) no emprego de inputs estabelecidos quando determinadas DMUs tomam decisões similares. Para realização do cálculo foram desenvolvidos dois modelos clássicos de análise, o modelo Charnes, Cooper e Rhodes (CCR), que leva em consideração retornos constantes de escala (Charnes, Cooper, \& Rhodes, 1978) e o modelo Banker, Charnes e Cooper (BCC), que leva em consideração retornos variáveis de escala (Banker, Charnes, \& Cooper, 1984).

Bandeira (2000) coloca que, na aplicação dos modelos, ainda pode-se escolher entre o cálculo orientado a input, isto é, dado determinado nível de output obter o emprego do mínimo possível de input ou orientado a output, que mantendo inputs fixos, se deseja atingir o máximo dos outputs.

Esta técnica ainda nos oferece uma fronteira de referência onde se encontram as DMUs eficientes e a distância em que DMUs ineficientes estão dessa fronteira. Ainda fornece um conjunto de DMUs referência que seriam espelhos de eficiência para DMUs ineficientes (benchmarks) (Lins et al., 2007).

Como abordado anteriormente, o modelo pode ser definido entre os clássicos CCR e BCC. Para o presente estudo, optou-se pelo modelo BCC, que leva em consideração retornos variáveis de escala (variables returns to scale[VRS]), definição que se baseou no estudo de Pedroso, Calmon e Bandeira (2009), que argumentam dizendo "que, em geral, as relações que se estabelecem na gestão de políticas públicas não supõem retornos constantes de escala". Conforme Banker, Charnes e Cooper (1984), matematicamente, o modelo passa a considerar a convexidade da fronteira, no caso da orientação output, temos a maximização de h. sujeito a:

$$
\begin{array}{r}
x_{i 0}-\sum_{k=1}^{n} x_{i k} \lambda_{k} \geq 0, \forall i \\
-h_{0} y_{j 0}+\sum_{k=1}^{n} y_{j k} \lambda_{k} \geq 0, \forall j \\
\sum_{k=1}^{n} \lambda_{k}=1 \quad \lambda_{k} \geq 0, \forall k
\end{array}
$$


A restrição de maximização de h. pressupõe que a intenção é maximizar os outputs (qualquer que seja .), dados valores fixos de inputs (qualquer que seja .) preestabelecidos, calculando-se a eficiência determinada através da relatividade entre DMUs (qualquer que seja .). O modelo BCC utilizado nesta pesquisa foi orientado a output, visto que o valor repassado do PBF, bem como a quantidade de famílias beneficiadas utilizados como inputs, são considerados dados e o objetivo do estudo é procurar estabelecer quais municípios melhor empregaram esses recursos no resultado final caracterizado pelas condicionalidades do programa e inseridos como outputs.

Conforme Mainardes, Alves e Raposo (2012), são vantagens desse método: A possibilidade de envolver e tratar inúmeros inputs e outputs, a não exigência de que as variáveis sejam parametrizadas, a possibilidade de medir a eficiência relativa, a não exigência de que exista uma relação funcional entre outputs e inputs, a identificação de unidades eficientes e o grau em que as ineficientes necessitam de melhoramento para serem eficientes. Os autores indicam igualmente limitações desse tipo de análise: Exige que as DMUs realizem atividades similares com objetivos em comum; é sensível à escolha das variáveis e, por isso, ocorre a utilização de variáveis não significativas; não mede a eficiência absoluta; é sensível a erros de medida e exige que o número de DMUs seja maior que o número de variáveis.

\section{Caracterização da pesquisa}

O estado do Paraná, recorte geográfico desta pesquisa, tem como característica ter uma acentuada desigualdade entre seus municípios, o que se reflete em mesorregiões muito heterogêneas. Conforme dados do Instituto Paranaense de Desenvolvimento Econômico e Social (IPARDES) (2017a), no ano censitário de 2010, dentre as 10 mesorregióes, o Centro Sul obteve o pior Índice de Gini, a renda média mais baixa, o pior índice de desenvolvimento humano municipal (IDHM), a maior taxa de pobreza e a segunda menor taxa de alfabetização. Em contraposição, a mesorregião Oeste encontra-se melhor do que a média paranaense em todos estes aspectos. Desta maneira, apesar de ser um dos estados com maior produto interno bruto (PIB) do Brasil, especialmente na agropecuária, dentro do estado, em diversos aspectos, existem desigualdade e carências.

O estado tem uma colonização ligada ao meio rural e à agricultura familiar, meio este que tem como tendência histórica o menor acesso à educação, saúde e outros recursos. Levando em consideração estes fatores históricos, bem como os dados apresentados, é relevante compreender a importância e impacto do PBF para as condicionalidades do programa, sendo essencial avaliar a eficiência do investimento feito pelo governo nesse sentido.

Optou-se pelos anos de 2006 e 2015 como recortes temporais, tendo em vista alguns critérios como a disponibilidade de variáveis, o período de tempo e os dados recentes. A intenção era compreender o maior período de tempo possível, com o intuito de comparar as possíveis mudanças. O ano de 2006 foi coletado pelo fato de que as variáveis de outputs possuíam informaçóes somente a partir desse ano. $\mathrm{O}$ ano de 2015 foi coletado por ser o ano mais recente para o qual estavam disponíveis os dados, também para os outputs. Desta maneira, foi possível criar um tempo relativo para comparação de mudanças de eficiência do programa dentro do estado.

Dos 399 municípios paranaenses, Nova Aliança do Ivaí e Santa Inês não foram incluídos na pesquisa por falta de dados em algumas variáveis utilizadas. O Quadro 3 mostra os inputs e outputs utilizados e a fonte de dados de cada variável. 
Quadro 3 - Variáveis e base de dados utilizados

\begin{tabular}{|l|l|l|l|}
\hline & Identificação & Variável & $\begin{array}{l}\text { Fonte de } \\
\text { Dados }\end{array}$ \\
\hline Inputs & INS1 & $\begin{array}{l}\text { Número de } \\
\text { familias } \\
\text { beneficiárias } \\
\text { Valor total } \\
\text { repassado } \\
\text { pelo } \\
\text { programa }\end{array}$ & MDS \\
\hline ONS2 & MRO1 & $\begin{array}{l}\text { Taxa de } \\
\text { aprovação } \\
\text { no ensino } \\
\text { médio } \\
\text { Taxa de não } \\
\text { distorção no } \\
\text { ensino } \\
\text { médio } \\
\text { Cobertura } \\
\text { vacinal total }\end{array}$ & IPARDES \\
\hline IPARDES \\
PRO2 & DRO3 & & \\
\hline
\end{tabular}

A variável "número de famílias beneficiárias" diz respeito à quantidade de famílias que recebem pelo menos uma das modalidades de benefício do PBF. A variável "valor total repassado pelo programa" infere sobre o valor total destinado a cada município individualmente. Essas duas variáveis são os inputs.

A variável "taxa de aprovação no ensino médio" compreende a proporção de alunos do total de matrículas em cada série do ensino médio que foram aprovados. A escolha pelo ensino médio baseou-se na saída dos alunos do ensino regular obrigatório, última fase que o programa condiciona adolescentes e jovens a manterse na escola. Esta variável procura captar a condicionalidade relacionada à educação: Como a intenção do programa é manter crianças, adolescentes e jovens no ensino regular através da condição de frequência escolar, este output compreende estabelecer uma relação entre a frequência e a taxa de aprovação.

A variável “taxa de não distorção do ensino médio" foi calculada subtraindo a taxa de distorção idade/série do ensino médio de $100 \%$. A taxa de distorção diz respeito à proporção de alunos em cada série do ensino médio com idade superior àquela recomendada, entre 15 e 17 anos. Para esta pesquisa, preferiu-se utilizar a taxa de alunos que tinham a idade recomendada para cada série do ensino médio (taxa de não distorção idade/ série), isto porque a metodologia utilizada pelo DEA procura aumentar os outputs levando em consideração os inputs e seria indesejado que se aumentasse a taxa de distorção idade/série, contudo, é desejado que a proporção de alunos com a idade recomendada aumente. Esta variável, assim como a anterior, tenta englobar a condicionalidade ligada a educação.

A variável “cobertura vacinal total” captura a condicionalidade associada à saúde. Uma das condições para a participação no programa é manter as vacinas atualizadas, logo, é esperado que, com a criação do programa, a cobertura vacinal aumente. A variável corresponde à taxa de pessoas imunizadas, ou seja, que receberam todas as vacinas básicas. Para alguns municípios observou-se taxas acima de 100\%. Segundo nota do IPARDES (2017b), com informações do Ministério da Saúde e Programa Nacional de Imunizações (MS-PNI), índices superiores a $100 \%$ podem estar relacionados a aplicação de vacinas em pessoas que demandam o município, mas que residem fora; imunização de pessoas fora da idade ou grupo indicado; problemas com o número de nascidos vivos que integra a fórmula de cálculo do indicador e (ou) casos de dupla vacinação.

O software utilizado para calcular os resultados foi o DEA SAED Software de Análise Envoltória de Dados, que é de uso livre e tem a possiblidade de utilização de número ilimitado de DMUs (Surco, 2004). 


\section{APRESENTAÇÃO E ANÁLISE DOS DADOS}

Conforme discutido anteriormente, o modelo utilizado para cálculo dos resultados é o BCC, com retornos variáveis de escala e orientado a output. Não há um padrão para apresentação dos resultados dos níveis de eficiência. Em geral, a literatura que utiliza a metodologia mostra os resultados para todas as observações ou faz uma divisão de acordo com o ajuste dos valores de eficiência observados. A metodologia indica que todas as observações que não obtêm coeficiente igual a 1 (um) são ineficientes. O que se pretende demonstrar subdividindo a ineficiência em níveis é que para aquelas observações mais próximas de 1 (um), é mais fácil organizar os recursos e tornar-se eficiente do que aquelas que obtiveram scores mais baixos. Como o número de observações, 397 ao todo para cada ano, é grande, optou-se pela subdivisão da ineficiência em níveis de $10 \%$, sendo que a maioria das observações se encontrava acima de 0,8. Assim, considerou-se ineficiência forte todas aquelas que possuíam eficiência com valor abaixo de 0,8 . Os resultados de eficiência para os dois anos, 2006 e 2015, estão indicados na Tabela 1.

Tabela 1 - Nível de eficiência por estratos para os anos de 2006 e 2015

\begin{tabular}{|c|c|c|c|}
\hline & \begin{tabular}{|l} 
Niveis de \\
Eficiência
\end{tabular} & \begin{tabular}{|l|} 
Número de \\
Municípios/DMUs
\end{tabular} & $\%$ \\
\hline \multirow{5}{*}{2006} & $\begin{array}{l}\text { Eficientes } \\
(=1)\end{array}$ & 11 & 2,77 \\
\hline & $\begin{array}{l}\text { Ineficiência } \\
\text { fraca (= } \\
0,9 \text { até } \geq \\
\text { 1) } \\
\end{array}$ & 109 & 27,46 \\
\hline & $\begin{array}{l}\text { Ineficiência } \\
\text { moderada } \\
(=0,8 \text { até } \\
\geq 0,9)\end{array}$ & 218 & 54,91 \\
\hline & $\begin{array}{l}\text { Ineficiência } \\
\text { forte }(> \\
0,8)\end{array}$ & 59 & 14,86 \\
\hline & Total & 397 & 100 \\
\hline \multirow{5}{*}{2015} & \begin{tabular}{|l} 
Eficientes \\
$(=1)$
\end{tabular} & 11 & 2,77 \\
\hline & $\begin{array}{l}\text { Ineficiência } \\
\text { fraca (= } \\
0,9 \text { até } \geq \\
1 \text { ) }\end{array}$ & 136 & 34,26 \\
\hline & $\begin{array}{l}\text { Ineficiência } \\
\text { moderada } \\
(=0,8 \text { até } \\
\geq 0,9) \\
\end{array}$ & 218 & 54,91 \\
\hline & $\begin{array}{l}\text { Ineficiência } \\
\text { forte }(> \\
0,8)\end{array}$ & 32 & 8,06 \\
\hline & Total & 397 & 100 \\
\hline
\end{tabular}

As DMUs consideradas eficientes foram 11 para cada um dos dois anos. Elas representam 2,77\% do total de municípios utilizados na pesquisa. Três DMUs tiveram, igualmente, máxima eficiência para os dois anos, correspondendo aos municípios de Miraselva, Quatro Pontes e Ivatuba. As DMUs eficientes estão representadas no Quadro 4, a seguir, com seus correspondentes municípios para os anos de 2006 e de 2015. 
Quadro 4 - DMUs eficientes e seus respectivos municípios para os anos de 2006 e 2015

\begin{tabular}{|l|l|l|l|}
\hline 2006 & 2015 \\
\hline DMU & Município & DMU & Município \\
\hline DMU13 & Anahy & DMU34 & $\begin{array}{l}\text { Bela Vista da } \\
\text { Caroba }\end{array}$ \\
\hline DMU17 & $\begin{array}{l}\text { Antônio } \\
\text { Olinto }\end{array}$ & DMU106 & $\begin{array}{l}\text { Entre Rios do } \\
\text { Oeste }\end{array}$ \\
\hline DMU44 & $\begin{array}{l}\text { Bom } \\
\text { Sucesso } \\
\text { do Sul }\end{array}$ & DMU146 & Iguatu \\
\hline DMU108 & $\begin{array}{l}\text { Espigão } \\
\text { Alto do } \\
\text { Iguaçu }\end{array}$ & DMU152 & Ipiranga \\
\hline DMU167 & Ivatuba & DMU167 & Ivatuba \\
\hline DMU213 & Maripá & DMU197 & Mallet \\
\hline DMU222 & Mercedes & DMU202 & Manfrinópolis \\
\hline DMU223 & Mirador & DMU224 & Miraselva \\
\hline DMU224 & Miraselva & DMU291 & $\begin{array}{l}\text { Quatro } \\
\text { Pontes }\end{array}$ \\
\hline DMU268 & Pinhalão & DMU309 & $\begin{array}{l}\text { Rio Branco do } \\
\text { Ivaí }\end{array}$ \\
\hline DMU291 & $\begin{array}{l}\text { Quatro } \\
\text { Pontes }\end{array}$ & DMU351 & $\begin{array}{l}\text { São Manoel } \\
\text { do Paraná }\end{array}$ \\
\hline
\end{tabular}

Com base da Tabela 1, pode-se inferir que a maior parte das DMUs, no caso, os municípios, está no estrato de ineficiência moderada, para os dois anos, com score de eficiência entre 0,8 e 0,9 , ou $80 \%$ e $90 \%$ de eficiência. Depois dos municípios considerados eficientes, o menor percentual de municípios está na faixa de ineficiência forte para os dois anos, com 59 e 32 municípios para 2006 e 2015, respectivamente. A Figura 1 demonstra a localização dos municípios e sua referida eficiência para os anos de 2006 e 2015. 

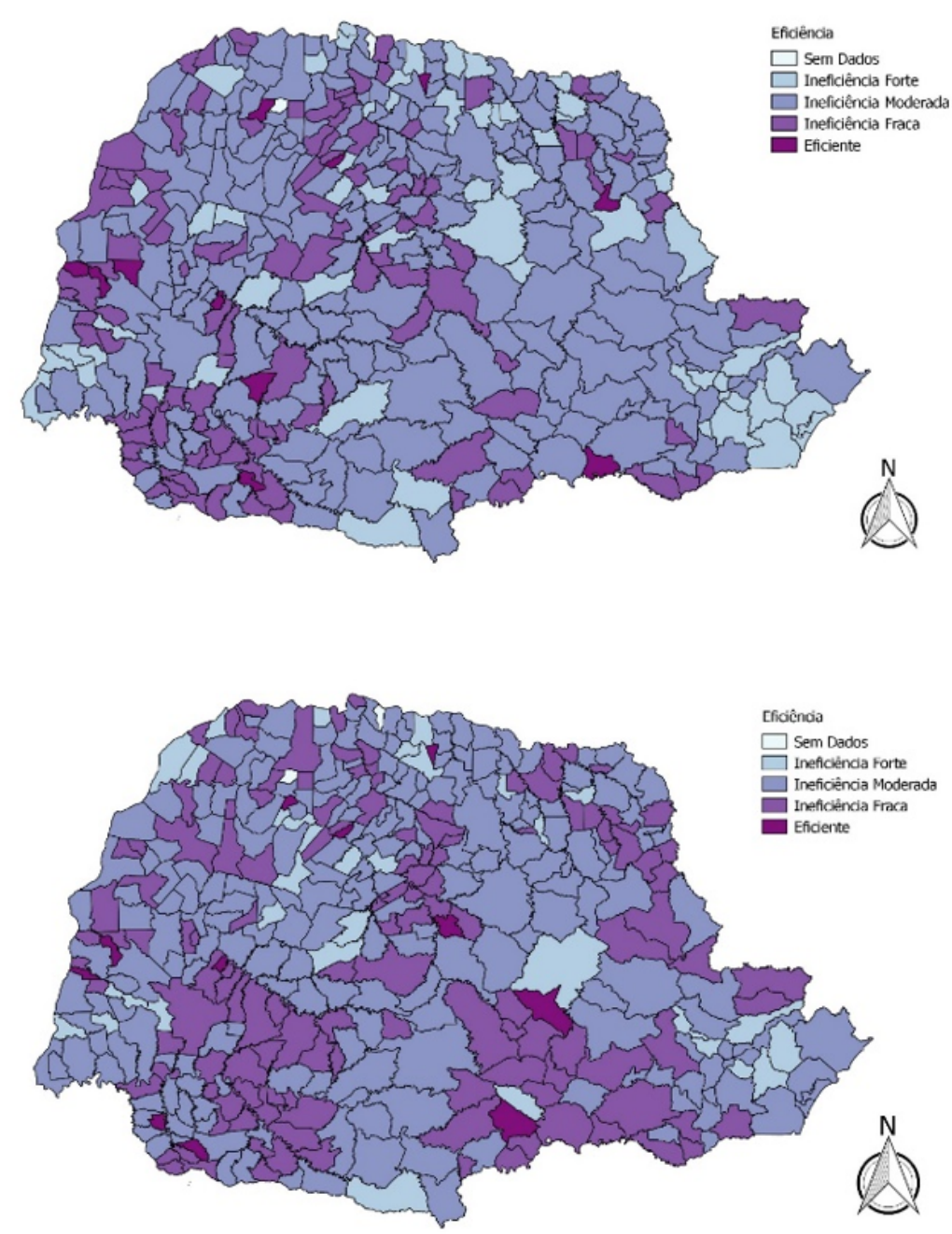

Figura 1 - Eficiência dos municípios do Paraná por estratos em 2006 e 2015, respectivamente

A Figura 1 mostra a localização dos municípios considerados eficientes para o ano de 2006 e para o ano de 2015, conforme legenda. Em 2006, pode-se verificar que dentre os 11 municípios eficientes, um encontrase na mesorregião Sudoeste Paranaense, um no Centro-Sul, um no Sudeste, um no Norte Pioneiro, dois no Norte Central Paranaense, um no Noroeste e quatro na mesorregião Oeste Paranaense. As mesorregiões Centro-Oriental, Centro-Ocidental e Metropolitana de Curitiba não tiveram municípios 100\% eficientes.

Para o ano de 2015, observa-se que dos 11 municípios eficientes, dois estão na mesorregião Sudoeste Paranaense, dois no Sudeste Paranaense, três no Norte-Central, um no Noroeste Paranaense e três na mesorregião Oeste Paranaense. As mesorregiões Metropolitana de Curitiba, Centro-Oriental, CentroOcidental, Centro-Sul e Norte Pioneiro Paranaense não tiveram municípios 100\% eficientes para o ano de 2015.

Com base nesta análise, pode-se observar que os municípios eficientes tenderam a uma concentração regional. No ano de 2006, das dez mesorregiões paranaenses, sete tinham municípios eficientes. Já no ano de 2015, cinco mesorregiões compreenderam os 11 municípios eficientes. Há uma relação entre essa concentração, tanto da renda quanto da eficiência, e o aumento das desigualdades entre as mesorregiôes, como indicado pelos dados do IPARDES (2017a). Existem muitas desigualdades entre as mesorregiões paranaenses, o que infere que, apesar de ser um estado que, em geral, tem um alto PIB, gerando muita renda e riqueza, elas são concentradas não somente entre as classes sociais, mas entre os municípios e as regiões. 
Kageyama e Hoffman (2006) apontam que o entendimento da pobreza e da condição social depende das percepções culturais e materiais de cada pessoa ou família, e a vivência em locais com grandes desigualdades afeta essa percepção. A inclusão social e material fornecida pelo acesso à renda através do PBF tende a mudar essa percepção, incentivando, por meio das condicionalidades, a escolarização e o cuidado com a saúde.

O objetivo geral das políticas de transferência de renda é, sobretudo, fazer com que as famílias não dependam dessa renda. Desta maneira, a desigualdade pode ser superada por meio da educação, da saúde e da geração de renda. Como indica a Organização das Nações Unidas (ONU) (2017), o Brasil deverá passar um momento de aumento das pessoas vivendo em situação de extrema pobreza e isso afetará as diferenças socais, de renda e a heterogeneidade entre as regiões. Observando a Figura 01 e fazendo uma ligação com as questões de pobreza e desigualdade, percebe-se que a ineficiência diminuiu entre os anos de 2006 e 2015, contudo, com as más expectativas indicadas pela $\mathrm{ONU}$ e com os resultados demonstrando uma concentração regional de eficiência, poderá deixar os resultados do programa piores.

Analisando essa situação, os desafios das políticas sociais serão potencializados pela condição econômica e política do país, por este motivo, tornar o programa eficiente é uma questão de bem-estar de toda a sociedade.

Além das eficiências, os resultados da pesquisa indiciam que as DMUs eficientes, chamadas de Benchmarks, tornam-se referência para as DMUs ineficientes. Cada DMU ineficiente pode ter mais do que uma DMU eficiente de referência. No ano de 2006, a DMU 223, que corresponde ao município de Mirador, foi benchmark de 267 municípios ineficientes, 67,25\% do total de municípios. No ano de 2015 a DMU 202, município de Manfrinópolis, foi benchmark de 343 municípios ineficientes, que corresponde a 86,40\% do total.

As Tabelas 2, 3, 4, 5 e 6 apresentam a estatística descritiva para os dados originais inseridos no software (coluna "Dados"), para seus valores mínimo, máximo, média e desvio-padrão, bem como as diferenças ou folgas (subtraindo a projeção dos dados) que seriam desperdícios ou falta de recursos. A última coluna demonstra o percentual das mudanças que resultaram nas diferenças (folgas) ${ }^{[i i i]}$.

A Tabela 2 evidencia os resultados obtidos para o input 01. Como observado, a média do número de famílias que recebem a transferência de renda dentre os municípios do Paraná reduziu do ano de 2006 para 2015 , de 1.138 para 1.007, aproximadamente. Visto pelo ângulo do menor e maior número de famílias, inferese que há diferenças significativas entre os municípios, sendo afetado pelo padrão do volume populacional, dentre outras variáveis. Por este motivo o desvio padrão do input é alto, revelando essas altas disparidades entre os municípios. A projeção máxima avaliada pelos resultados da pesquisa indicou que o máximo de famílias beneficiárias influenciando os resultados das condicionalidades poderia ser até $98,67 \%$ menor para o ano de 2006 e até $99,75 \%$ menor para o ano de 2015 . Com esse resultado, pode-se observar, parcialmente, que o número de famílias não é tão relevante para o aumento dos outputs selecionados.

Tabela 2 - Resultados da pesquisa para o input 01 - INS1 - Número de Famílias Beneficiárias

\begin{tabular}{l|l|l|l|l|l}
\hline Anos & Tipo & Dados & Projeção & Diferença & $\%$ \\
\hline \multirow{4}{*}{2006} & Mínimo & 76 & 76 & 0 & 0 \\
\cline { 2 - 6 } & Máximo & 35917 & 476,15 & $-35440,85$ & $-98,67$ \\
\cline { 2 - 6 } & Média & 1138,42 & 320,01 & $-818,41$ & $-46,38$ \\
\cline { 2 - 6 } & $\begin{array}{l}\text { Desvio } \\
\text { Padrão }\end{array}$ & 2267,39 & 140,46 & 2238,98 & 29,67 \\
\hline \multirow{4}{*}{2015} & Mínimo & 45 & 45 & 0 & 0 \\
\cline { 2 - 6 } & Máximo & 31236 & 873 & $-31159,10$ & $-99,75$ \\
\cline { 2 - 6 } & Média & 1007,49 & 194,75 & $-812,74$ & $-54,36$ \\
\cline { 2 - 6 } & $\begin{array}{l}\text { Desvio } \\
\text { Padrão }\end{array}$ & 2151,91 & 152,86 & 2160,80 & 35,15 \\
\hline
\end{tabular}


A Tabela 3 anuncia os resultados para o input 02, valor repassado aos municípios pelo programa, também visto em função do número de famílias beneficiadas e tamanho da população. Como observado para o input 01, as diferenciações em valores também são grandes. A média teve aumento, de 2006 para 2015, de R $\$ 728.503,30$ para $\mathrm{R} \$ 1.722 .486,16$. O percentual máximo de redução indicado para 2006 foi de 98,51\% e para 2015 de 99,75\%. Esse resultado corrobora com os resultados obtidos para o input 01, onde reduções expressivas nas duas variáveis proporcionariam resultados semelhantes nos outputs. Isso indica que há desperdícios (folgas) nos investimentos feitos pelo programa.

Tabela 3 - Resultados da pesquisa para o input 02 -

INS2 - Valor Total Repassado pelo Programa (em R\$)

\begin{tabular}{c|l|l|l|l|l}
\hline Anos & Tipo & Dados & Projeção & Diferença & $\%$ \\
\hline \multirow{4}{*}{2006} & Mínimo & $33.522,00$ & $33.522,00$ & - & 0 \\
\cline { 2 - 6 } & Máximo & $23.397 .521,00$ & $347.454,18$ & $23.050 .066,82$ & $-98,51$ \\
\cline { 2 - 6 } & Média & $728.503,30$ & $219.086,64$ & $-509.416,66$ & $-41,17$ \\
\cline { 2 - 6 } & $\begin{array}{l}\text { Desvio } \\
\text { Padrão }\end{array}$ & $1.477 .534,05$ & $109.038,38$ & $1.456 .422,69$ & 33,14 \\
\hline \multirow{4}{*}{2015} & Mínimo & $65.290,00$ & $65.290,00$ & - & 0 \\
\cline { 2 - 7 } & Máximo & $52.382 .081,00$ & $1.308 .109,00$ & $-52.252 .136,83$ & $-99,75$ \\
\cline { 2 - 6 } & Média & $1.722 .486,16$ & $322.346,31$ & $-1.400 .139,85$ & $-55,40$ \\
\cline { 2 - 6 } & $\begin{array}{l}\text { Desvio } \\
\text { Padrão }\end{array}$ & $3.614 .922,45$ & $246.786,55$ & $3.628 .461,95$ & 35,08 \\
\hline
\end{tabular}

Com base na Tabela 4, que representa os resultados para o output 01 , "taxa de aprovação escolar no ensino médio", pode-se avaliar que a média aumentou de 2006 para 2015, passando de $74,94 \%$ para 80,89\%. Levando em consideração os valores dos inputs 01 e 02 , os resultados mostraram que a projeção para o output 01 poderia ter sido, na média, para o ano de 2006 , de $87,21 \%$ e no ano de 2015 de $93,01 \%$, aumento médio de $17,35 \%$ e $16 \%$, respectivamente.

Tabela 4 - Resultados da pesquisa para o output 01 - PRO1 - Taxa de Aprovação no Ensino Médio

\begin{tabular}{l|l|l|l|l|l}
\hline Anos & Tipo & Dados & Projeção & Diferença & $\%$ \\
\hline \multirow{4}{*}{2006} & Mínimo & 45,20 & 73,00 & 0,00 & 0 \\
\cline { 2 - 6 } & Máximo & 98,80 & 98,80 & 30,28 & 66,99 \\
\cline { 2 - 6 } & Média & 74,94 & 87,21 & 12,27 & 17,35 \\
\cline { 2 - 6 } & $\begin{array}{l}\text { Desvio } \\
\text { Padrã̃o }\end{array}$ & 7,89 & 3,71 & 5,88 & 10,08 \\
\hline \multirow{4}{*}{2015} & Mínimo & 60,50 & 77,40 & 0,00 & 0 \\
\cline { 2 - 6 } & Máximo & 97,40 & 97,40 & 30,53 & 50,47 \\
\cline { 2 - 6 } & Média & 80,89 & 93,01 & 12,11 & 16,00 \\
\cline { 2 - 6 } & $\begin{array}{l}\text { Desvio } \\
\text { Padrão }\end{array}$ & 6,24 & 2,32 & 6,00 & 8,99 \\
\hline
\end{tabular}

A Tabela 5 espelha os resultados obtidos para o output 02 . A média de alunos que estavam na série correta para a idade recomendada foi de 68,49\% em 2006 e de 77,42\% em 2015, mostrando um aumento, enquanto que a projeção média indicada foi de $79,56 \%$ e $89,35 \%$, respectivamente. 
Tabela 5 - Resultados da pesquisa para o output 02 - PRO2 - Taxa de Não Distorção no Ensino Médio

\begin{tabular}{l|l|l|l|l|l}
\hline Anos & Tipo & Dados & Projeção & Diferença & $\%$ \\
\hline \multirow{4}{*}{2006} & Minimo & 0,00 & 57,40 & 0,00 & 0 \\
\cline { 2 - 6 } & Máximo & 89,40 & 89,40 & 67,96 & 60,94 \\
\cline { 2 - 6 } & Média & 68,49 & 79,56 & 11,07 & 16,83 \\
\cline { 2 - 6 } & $\begin{array}{l}\text { Desvio } \\
\text { Padrão }\end{array}$ & 9,67 & 7,34 & 6,00 & 9,64 \\
\hline \multirow{4}{*}{2015} & Mínimo & 52,40 & 68,20 & 0,00 & 0 \\
\cline { 2 - 6 } & Máximo & 93,80 & 93,80 & 30,00 & 57,25 \\
\cline { 2 - 6 } & Média & 77,42 & 89,35 & 11,93 & 16,00 \\
\hline & $\begin{array}{l}\text { Desvio } \\
\text { Padrão }\end{array}$ & 6,86 & 3,71 & 5,95 & 9,57 \\
\hline
\end{tabular}

Os resultados encontrados para o output 03 são exibidos pela Tabela 6, segundo a qual, na média, houve aumento de $77,72 \%$ em 2006 para 101,30\% ${ }^{\text {[iv] }}$ em 2015. Esses percentuais poderiam ser melhores, levando em consideração os inputs 01 e 02, em média de 16,29\% para 2006 e de 15\% para 2015.

Tabela 6 - Resultados da pesquisa para o output 03 - PRO3 - Cobertura Vacinal Total

\begin{tabular}{l|l|l|l|l|l}
\hline Anos & Tipo & Dados & Projeção & Diferença & $\%$ \\
\hline \multirow{4}{*}{2006} & Mínimo & 46,81 & 65,79 & 0,00 & 0 \\
\cline { 2 - 6 } & Máximo & 116,49 & 116,49 & 34,29 & 52,30 \\
\cline { 2 - 6 } & Média & 77,72 & 90,08 & 12,36 & 16,29 \\
\cline { 2 - 6 } & $\begin{array}{l}\text { Desvio } \\
\text { Padrão }\end{array}$ & 7,23 & 7,95 & 6,58 & 9,19 \\
\hline \multirow{4}{*}{2015} & Mínimo & 41,36 & 58,33 & 0,00 & 0 \\
\cline { 2 - 6 } & Máximo & 200,00 & 200,00 & 46,02 & 66,44 \\
\cline { 2 - 6 } & Média & 101,30 & 115,76 & 14,45 & 15,00 \\
\cline { 2 - 6 } & $\begin{array}{l}\text { Desvio } \\
\text { Padrão }\end{array}$ & 20,39 & 20,28 & 7,55 & 8,81 \\
\hline
\end{tabular}

Exposto pelos resultados obtidos para os inputs 01 e 02 e para os outputs 01,02 e 03 , pode-se visualizar que o aumento da renda transferida poderia ter sido melhor gerido para ser mais eficiente na grande maioria dos municípios e conduzir a melhores indicadores de saúde e educação, avaliados pelas variáveis selecionadas nesta pesquisa.

Dos 19 municípios considerados eficientes entre os anos de 2006 e 2015, o maior deles possui pouco menos de 15.000 habitantes. Brambilla (2015), analisando a gestão do PBF no Paraná, obteve resultados que indicaram que municípios com população menor possuem melhor gestão do programa, o que confirma os resultados da presente pesquisa. Melgarejo (2011) apontou em sua pesquisa para as falhas de gestão a nível municipal, especialmente pela falta de capital humano qualificado para gerir os recursos. Santana (2016) encontrou resultados semelhantes para Campina Grande (PB) nessa questão.

Apesar desse resultado, pode-se verificar que houve um aumento expressivo na média de imunização por vacinação no estado entre os dois anos analisados, um bom resultado na área de saúde para os municípios. Neste sentido, nota-se também o aumento do percentual total da taxa de aprovação dos alunos do ensino médio e da taxa de não distorção idade/série, um avanço nos resultados educacionais paranaenses. Na esfera educacional, este estudo se assemelha ao resultado obtido por Cacciamali et al. (2010) para o Brasil, no qual concluíram que o programa foi eficiente para elevar a frequência escolar. Araújo et al. (2015) propõem também que o aumento dos recursos empregados pelo programa não elevou proporcionalmente os benefícios 
medidos através de indicadores. Os dados representados pelas folgas para cada variável representam que houve desperdício de recurso que, bem administrado, poderia ter trazido mais benefícios.

Conforme concluído e defendido por Lagura (2012), é função do governo identificar as lacunas dentro do programa: Se há má gestão, é preciso encontrar onde acontece e procurar corrigir, da mesma maneira que outras esferas precisam ser contempladas juntamente com as ações paliativas do imediatismo do programa. Conforme observado por Hespanha (2008), é uma falha das políticas públicas de transferência de renda não considerar a inserção no mercado de trabalho, como no PBF não há objetivos direcionados a esse setor.

Martic et al. (2009) exploraram os usos para a metodologia da Análise Envoltória de Dados e indicaram ser um bom instrumento de análise de eficiência de políticas públicas, assim como feito neste estudo, que objetivou avaliar a eficiência do PBF como política pública condicionante, levando em consideração a saúde e a educação. Corrobora com os resultados encontrados por Habibov e Fan (2010), em que a utilização da metodologia DEA proporciona aos gestores públicos alicerces para a tomada de decisões no que diz respeito ao PBF como política pública transversal.

A partir das evidências empíricas e dos resultados obtidos com a pesquisa, é necessário evidenciar que o PBF não tem atingido uma eficiência plena. Ainda há muitas divergências e incoerências no programa, o que faz ser essencial uma avaliação periódica e atenciosa, no que diz respeito à aplicação desses recursos.

Assim, uma indicação é que o gerenciamento do programa precisa de metas mais bem definidas, assim como uma autocrítica sobre a eficiência e a gestão da operacionalização dos recursos. Uma opção para melhorar esses resultados é criar alternativas de geração de renda direta para as famílias beneficiárias, porque, apesar da garantia da educação e da saúde, não há um incentivo direto para a geração de empregos, de empreendedorismo, nem oportunidades para isso.

Dito isso, compreendemos ainda que famílias que habitam o meio rural, por exemplo, ou locais isolados, têm ainda menos acesso a universidades, a especializações, cursos técnicos, dentre outras oportunidades de escolarização e de geração de renda. Por isso, tratar cada local de maneira singular é outra maneira de melhorar esses resultados, que têm sido genéricos em inserir uma renda de subsistência àquelas famílias extremamente pobres.

A crítica principal ao programa é a falta de inserção das famílias no mercado de trabalho, que acaba por ser um dos fatores mais importantes para que se supere o ciclo da pobreza. Os objetivos do programa deveriam passar por um processo de reconstrução audacioso, que proporcionasse aos jovens a inserção social, cultural e de renda e que lhes permitisse construir um meio de vivência que incentivasse a superação das condições de vida precárias.

As transferências de renda do governo são importantes na medida em que garantem condições mínimas de sobrevivência, mas a superação dessa condição provém da educação e da saúde, áreas nas quais o programa já atua, e na geração de renda própria, que ainda é uma lacuna.

Observando os resultados da pesquisa, a literatura relacionada e a discussões dessas relações, instiga-se que há oportunidades de melhoramento do programa, que há brecha de gestão, de avaliação e de objetivos audaciosos que melhorem a eficiência do investimento de recursos do governo com a política. As pesquisas relacionadas à avaliação de políticas públicas são uma boa oportunidade para gestores de rever as práticas e utilizá-las como uma base para melhorar os resultados e o bem-estar de toda a sociedade.

\section{CONSIDERAÇÕES FINAIS}

A pesquisa demonstrou melhoras nos indicadores selecionados nas áreas de saúde e educação do ano 2006 para 2015, mesmo que, observado pelos resultados da aplicação da metodologia DEA, poderiam ter sido ainda melhores. 
O gerenciamento do valor repassado pelo programa cabe aos municípios, assim como a identificação e o cadastramento das famílias prioritárias. A maneira de conduzir o programa é particular de cada município, isso proporciona grandes diferenciações entre eles.

A pesquisa contribui para a avaliação do PBF e gera sugestões para o seu melhoramento. Indica-se que o programa poderia ter um melhor gerenciamento e uma aplicação mais eficiente, começando pelos recursos humanos que gerenciam os recursos. Além disso, romper com o ciclo da pobreza e da desigualdade ainda depende da inserção das famílias no mercado de trabalho, para que não dependam dos recursos do governo, mas para que possam aumentar sua renda e, consequentemente, sua qualidade de vida.

Para novas pesquisas, indica-se a utilização de outras variáveis que expressem as condicionalidades do programa, bem como a utilização de outros inputs que versam sobre as condições dos municípios em questões populacionais e de renda per capita, a fim de captar essas diferenciações. Variáveis como o Índice de Gini e o Índice de Desenvolvimento Humano (IDH) seriam possíveis de serem utilizadas com a mesma metodologia, analisando por outro lado a relação entre o PBF e a pobreza. Seria possível também regionalizar a análise, com o intuito de verificar padrões regionais e espaciais de eficiência, se há indícios estatísticos de heterogeneidade regional. Outra indicação de pesquisa futura seria a aplicação para outros estados brasileiros e ainda, fazer a análise utilizando dados anteriores e posteriores ao início do PBF, com objetivo de elucidar as diferenciações ocorridas pela implantação do programa, utilizando a metodologia DEA ou outras.

\section{REFERÊNCIAS}

Araújo, F. R., Araújo, M. A. D., Souza, F. J. V., Santos, D. F., Santana, M. B. (2015). Uma avaliação do Índice de Gestão Descentralizada do Programa Bolsa Família. Revista Administração Pública, 49(2), 367-393.

Bandeira, D. L. (2000). Análise da eficiência relativa de departamentos acadêmicos - o caso da UFRGS (Dissertação de Mestrado). Universidade Federal do Rio Grande do Sul, Porto Alegre, RS, Brasil.

Banker, R. D., Charnes, A., Cooper, W. W. (1984). Some models for estimating technical and scale inefficiencies in data envelopment analysis. Management Science, 30(9), 1078-1092.

Brambilla, M. C. (2015). Análise da eficiência da gestão do Programa Bolsa Familia nos municípios do Paraná (Dissertação de Mestrado). Universidade Estadual de Londrina, Londrina, PR, Brasil.

Constituição da República Federativa do Brasil de 1988. (1988). Recuperado de: http://www.planalto.gov.br/ccivil_0 3/constituicao/constituicao.htm.

Cacciamali, M. C., Tatei, F., Batista, N. F. (2010). Impactos do Programa Bolsa Família Federal sobre o trabalho infantil e a frequência escolar. Revista de Economia Contemporânea, 14(2), 269-301.

Caixa Econômica Federal. (2017). Bolsa Família. Recuperado, em 17 de junho de 2017, de: http://www.caixa.gov.br/ programas-sociais/bolsa-familia/Paginas/default.aspx.

Charnes, A. Cooper, W. W., Rhodes. E. (1978). Measuring the efficiency of decision making units. European Journal of Operational Research, 2(6), 429-444.

Claim Child Benefit. (2017). Child Benefit. Recuperado, em 28 de junho de 2017, de: https://www.gov.uk/child-be nefit/overview.

Costa, V. M., Vita, A., Pralon, E. M. (1998). Reformas das politicas sociais num contexto de descentralização: o papel dos programas municipais de garantia de renda minima no combate a pobreza. Centro de Estudos de Cultura Contemporânea, São Paulo: Cedec.

Decreto no 8.794 de 29 de junho de 2016. (2016). Altera o Decreto n. 5.209, de 17 de setembro de 2004, que regulamenta a Lei no 10.836, de 9 de janeiro de 2004, que cria o Programa Bolsa Família .... Diário Oficial da União, Brasília, DF. Recuperado, em 16 de junho de 2017, em: http://www.planalto.gov.br/ccivil_03/_Ato2015-2018/2016/ Decreto/D8794.htm\#art1.

Deutschland. (2017). BundesagenturFur Arbeit (BA) - Regierung von Deutschland. Recuperado, em 26 de junho de 2017, de: https://www.arbeitsagentur.de/. 
Habibov, N. N., Fan, L. (2010). Comparing and contrasting poverty reduction performance of social welfare programs across jurisdictions in Canada using Data Envelopment Analysis (DEA): An exploratory study of the era of devolution. Evaluation and program planning. Evaluation and Program Planning, 33(4), 457-467.

Hagenaars, A., Vos, K. D. (1988). The definition and measurement of poverty. The Journal of Human Resources, 23(2), 211-221.

Hespanha, P. (2008). Políticas sociais: novas abordagens, novos desafios. Revista de Ciências Sociais, 39(1), 5-15.

Instituto Paranaense de Desenvolvimento Econômico e Social. (2017a). Base de dados do estado - BDEweb. Recuperado, em 08 de janeiro de 2019, em: http://www.ipardes.pr.gov.br/imp/index.php.

Instituto Paranaense de Desenvolvimento Econômico e Social. (2017b). Nota Informativa. Recuperado, em 21 de junho de 2017, em: http://www.ipardes.pr.gov.br/imp/imp.php?page=varinfpop\&var=2503.

Kageyama, A., Hoffman, R. (2006). Pobreza no Brasil: uma perspectiva multidimensional.Economia e Sociedade, 15(1), 79-112.

Lagura, G. B. (2012). Social welfare policy in the Philippines: an analysis. College of Governance Business, 1(1), 246-254.

Lei no 8.742 de 7 de dezembro de 1993. (1993). Dispõe sobre a organização da Assistência Social e dá outras providências. Diário Oficial da União, Brasília, DF. Recuperado, em 15 de junho de 2017, em: http://www.pla nalto.gov.br/ccivil_03/leis/L8742compilado.htm.

Lei no 10.836 de 09 de janeiro de 2004. (2004). Cria O Programa Bolsa Família e dá outras providências. Diário Oficial da União, Brasília, DF. Recuperado, em 17 de junho de 2017, em: http://www.planalto.gov.br/ccivil_03/_ato 2004-2006/2004/lei/110.836.htm.

Lins, M. E., Lobo, M. S. C., Silva, A. C. M., Fiszman, R., Ribeiro, V. J. P. (2007). O uso da análise envoltória de dados (DEA) para avaliação de hospitais universitários brasileiros. Revista Ciência e Saúde Coletiva, 12(4), 985-998.

Mainardes, E. W., Alves, H., Raposo, M. (2012). O desempenho das universidades públicas portuguesas segundo seus alunos: análise de eficiência por meio do Data Envelopment Analysis. Revista GUAL, 5(1), p. 184-215.

Marconi, M. A., Lakatos, E. M. (2012). Técnicas de pesquisa: planejamento e execução de pesquisas, amostragense técnicas de pesquisa, elaboração, análise e interpretação de dados. 7 Ed. São Paulo: Atlas.

Martic, M. M., Novakovic, M. S., Baggia, A. (2009). Data envelopment analysis - Basic models and their utilization. Organizacija, 42(2), 37-43.

Melgarejo, A. P. B. (2011). Eficiência do controle do Programa Bolsa Familia na perspectiva da gestão por resultados (Dissertação de Mestrado). Fundação Getúlio Vargas, Escola Brasileira de Administração Pública e de Empresas, Brasília, Brasil.

Ministério do Desenvolvimento Social e Combate à Fome. (2017) Bolsa Familia: Condicionalidades. Recuperado, em 18 de junho de 2017, em: http://mds.gov.br/assuntos/bolsa-familia/gestao-do-programa/condicionalidades.

Mota, F. L. (2014). Efciência relativa na gestão de dos recursos públicos: uma análise do Instituto Federal de Educą̧ão, Ciência e Tecnologia da Bahia (Dissertação de Mestrado). Universidade Federal da Bahia, Salvador, Bahia, Brasil.

Organização das Nações Unidas. (2017). Número de pobres no Brasil terá aumento de no mínimo 2,5 milhões em 2017, aponta Banco Mundial. Recuperado, em 18 de junho de 2017, em: https://nacoesunidas.org/numero-de-pobre s-no-brasil-tera-aumento-de-no-minimo-25-milhoes-em-2017-aponta-banco-mundial/.

Pedroso, M. M., Calmon, P. C. D. P., Bandeira, L. F. (2009). O uso da Análise Envoltória de Dados para a avaliação do Programa Bolsa Família. Com. Ciências Saúde, 20(1), 37-44.

Santana, L. K. A. (2016). Avaliação do impacto do Programa Bolsa Família no município de Campina Grande-PB (Trabalho de Conclusão de Curso). Universidade Estadual da Paraíba, Campina Grande, PB, Brasil.

Silva, M. O. S. (2007). O Bolsa Família: problematizando questões centrais na política de transferência de renda no Brasil. Revista Ciência e Saúde Coletiva, 12(6), 1429-1439.

Surco, D. F. (2004). Desenvolvimento de uma ferramenta computacional para avaliação da eficiência técnica baseada em DEA (Dissertação de Mestrado). Universidade Federal do Paraná, Curitiba, PR, Brasil. 


\section{NoTAS}

[i]Eficiência de um município com relação a outro que utiliza os mesmos insumos a fim de obter os mesmos resultados ou produtos praticando tarefas similares (Mota, 2014).

[ii] "Poverty is having less than an objectively defined, absolute minimum; Poverty is having less than others in society; Poverty is feeling you do not have enough to get along" (Hagenaars, \& Vos, 1988, p. 212).

[iii]As folgas representam a diferença que um recurso foi utilizado a mais (negativo) ou a menos (positivo) e o percentual mostra a variação dessa diferença entre a projeção dos valores necessários e os valores reais utilizados.

[iv]Conforme descrito neste estudo, há razões para que a taxa de vacinação possa ser maior que 100\%.

\section{BY-NC-ND}

